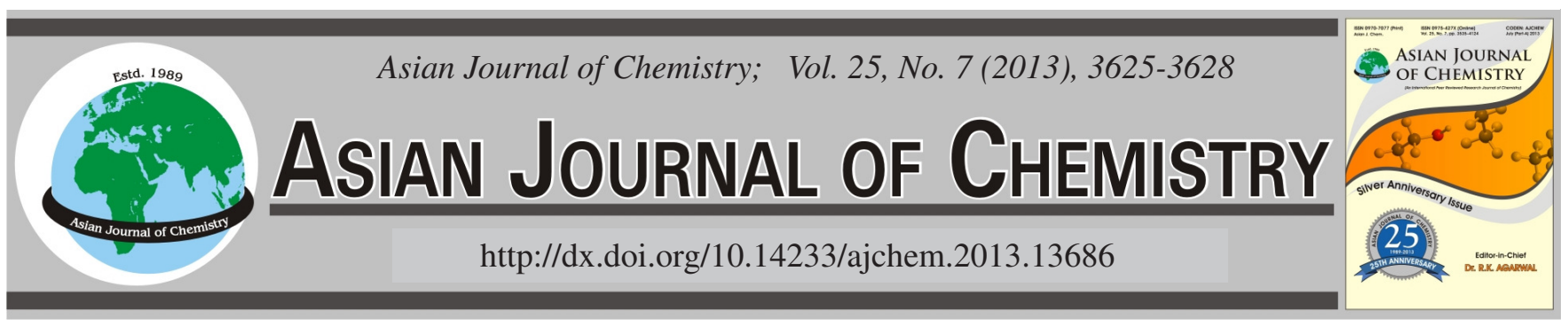

\title{
Synthesis and Properties of Novel Polyazobenzene
}

\author{
Weiwei Li and Dongmei Xu*
}

College of Chemistry, Chemical Engineering and Materials Science, National Engineering Laboratory for Modern Silk, Key Laboratory of Organic Synthesis of Jiangsu Province, Jiangsu Key Laboratory of Advanced Functional Polymer Design and Application, Soochow University, Suzhou, Jiangsu 215123, P.R. China

*Corresponding author: Fax: +86 512 65880089; Tel: +86 512 65882027; E-mail: xdm.sd@163.com

A novel aromatic polyazo compound 1,2-bis[4-((4,6-bis((4-phenyl diazenyl)phenoxy)-1,3,5-triazin-2-yl)oxy)phenyl]diazene with five azobenzene units was facilely constructed by dehydrochlorination reaction between $p$-hydroxyazobenzene, 4,4'-dihydroxyazobenzene and cyanuric chloride under very mild conditions. Compared to azobenzene, the crystallinity of polyazo compound with five azobenzene units greatly decreased, while the thermostability remarkably improved. The maximal absorption wavelength of polyazo compound with five azobenzene units was close to that of azobenzene, but the molar extinction coefficient of polyazo compound with five azobenzene units was near five times of that of azobenzene. Polyazo compound with five azobenzene units exhibited typical reversible photoisomerization behaviours and was expected to be applied in photonic material areas.

Key Words: Azo compound, Cyanuric chloride, Crystallinity, Thermostability, Photoisomerization.

\section{INTRODUCTION}

Azobenzene $(\mathrm{AB})$ and its derivatives are the most representative and well-known photochromic molecules ${ }^{1-3}$, which occur clean and reversible photoisomerization between the trans (E) and cis (Z) forms upon irradiation with UV or visible light ${ }^{4-7}$. The photoisomerization of azobenzene compounds can be used to trigger reversible changes of various properties by light, which is the basis for many valuable applications including optical switches ${ }^{8-11}$, information storage ${ }^{12-15}$, protein folding $^{16,17}$, artificial molecular motors ${ }^{18,19}$. Micromechanics ${ }^{20-22}$ and other materials with photomodulable properties. Aromatic polyazobenzene were mainly constructed by means of diazo coupling ${ }^{23-26}$ and polymerization of azobenzene-containing monomers ${ }^{27-29}$. Diazo coupling requires carefully controlled temperatures and produce significant amounts of pollution. Polymerization is a fast and simple method for achieving polyazo dyes, but the indefinite structure of the products sometime limits the study on property and application. By contrast, the reaction of judiciously chosen reagents with substitutional azobenzenes can efficiently achieve products with welldefined structures and novel designed properties.

In this paper, we designed and synthesized a novel aromatic polyazo compounds with well-defined structures and its crystallinity, thermostability, UV-visible absorption properties and photoisomerization behaviours were carefully examined.

\section{EXPERIMENTAL}

Cyanuric chloride (CNC) $(99.0 \%)$ was purchased from Shanghai yiri chemical technology Co., Ltd., azobenzene (AB) was provided by Yake Chemical Reagent Co., Ltd., phydroxyazobenzene ( $p$-HAB) was obtained from China Medicine Group Shanghai Chemical Reagent Co., Ltd., N,Ndiisopropyl ethylamine (DIPEA) $(99.0 \%)$ was provided by Jiande New Delhi Chemical Co., Ltd., sodium hydroxide $(\mathrm{NaOH})$ and solvents were commoditis of Sinopharm Chemical Reagent Co., Ltd. All the reagents were used as received.

IR was recorded on a Nicolet Magan-550 spectrometer (Nicolet Co., USA). LC-MS was collected on an Agilent 1200/ 6220 spectrometer (Agilent Co., USA). The solid NMR experiments were performed with a $4 \mathrm{~mm}$ triple-resonance probe on a Bruker AVANCE III-500 spectrometer (Bruker Co., Switzerland) operated at a magnetic field strength of $11.7 \mathrm{~T}$ (Pulse widths $(\mathrm{p} / 2)$ for ${ }^{1} \mathrm{H}$ and ${ }^{13} \mathrm{C}$ were measured to be 3.15 and $4.2 \mu$ s, respectively). The elementary analysis was measured on a Carlo-Erba EA1110 CHNO-S (Carlo-Erba Co., Italy). Crystallinity was taken on a X'PERT PRO MPD (PANalytical Company, Holland). Thermo gravimetric analysis (TGA) was tested using a SDT 2960 Simultaneous DSC-TGA instrument (PA Company, USA). UV-VIS spectra were obtained on a 
U-3900 spectrophotometer (Perkin-Elmer Co., USA) (Slit width: $2 \mathrm{~nm}$; T: $25^{\circ} \mathrm{C}$ ). Photo irradiation was provided by a ZF-20D black-box-type ultraviolet analyzer (Shanghai Yuzheng Instrument Equipment Co. Ltd., China).

General procedure and characterization data: 4,4'Dihydroxyazobenzene (DHAB) and 2-chloro-4,6-bis(4(phenyldiazenyl)phenoxy)-1,3,5-triazine (DOT) were prepared according to literature procedures ${ }^{30,31}$. DOT $(0.2788 \mathrm{~g}, 0.55$ mmol) was dissolved in 1,4-dioxane $(5 \mathrm{~mL})$ and mixed with 1,4-dioxane solution ( $5 \mathrm{~mL})$ of DHAB $(0.0535 \mathrm{~g}, 0.25 \mathrm{mmol})$ and DIPEA $(0.10 \mathrm{~mL}, 0.55 \mathrm{mmol})$ under stirring. The reaction was carried out in oil bath at $80^{\circ} \mathrm{C}$ for $36 \mathrm{~h}$. Then, 1,4-dioxane was removed with a rotary evaporator. The residue was cooled down to room temperature and washed with $\mathrm{H}_{2} \mathrm{O}(10 \mathrm{~mL})$ and acetone $(10 \mathrm{~mL} \times 3 \mathrm{~mL})$, dried under vacuum to get $0.1722 \mathrm{~g}$ (59.6\%) orange solid 1,2-bis(4-(4,6-bis((4-phenyldiazenyl)phenoxy)-1,3,5-triazin-2-yl)oxy)-phenyl)diazene (POT): m.p. 275.6-276.4 ${ }^{\circ} \mathrm{C}$; ${ }^{1} \mathrm{H}$ MAS NMR (magnetic field strength 11.7 $\mathrm{T}$, spinning speed $8 \mathrm{kHz}$, pulse time $3.15 \mu \mathrm{s}) \delta: 6.65(44 \mathrm{H}$, $\mathrm{ArH})$, the peaks marked with an asterisk were the rotating band during the experiment; ${ }^{13} \mathrm{C} \mathrm{CP} / \mathrm{MAS}$ TOSS (magnetic field strength $11.7 \mathrm{~T}$, spinning speed $8 \mathrm{kHz}$, pulse time, 4.20

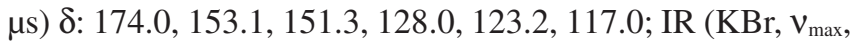
$\mathrm{cm}^{-1}$ ): 1569, 1493, 1362 (phenyl and $s$-triazine ring), 1201 (C-N), 1010 (C-O-C); LC-MS m/z: $1157.3723\left(\mathrm{M}+\mathrm{H}^{+}\right)$. Anal. calcd. (\%) for $\mathrm{C}_{66} \mathrm{H}_{44} \mathrm{~N}_{16} \mathrm{O}_{6}$ : C 68.50, H 3.83, N 19.37; found (\%) C 67.43, H 3.90, N 18.94.

X-Ray diffraction (XRD) test: X-ray diffraction (XRD) was taken on a Rigaku D/max-2200 (Rigaku, Japan, $\mathrm{CuK}_{\alpha}, \lambda$ $=1.54056 \mathrm{~nm}$ ) with a voltage of $40 \mathrm{kV}$ and a current of 40 $\mathrm{mA}$. The diffraction pattern was collected over the $2 \theta$ range $2-70^{\circ}$ with a scanning speed of $0.215629\left({ }^{\circ}\right) \mathrm{s}^{-1}$ and a step size of $0.0334^{\circ}$.

Thermogravimetric analysis: $\mathrm{AB}$ and $\mathrm{POT}$ were heated on a SDT 2960 Simultaneous DSC-TGA instrument at the rate of $20 \mathrm{~K} / \mathrm{min}$ in a nitrogen inert atmosphere with the flow rate of $20 \mathrm{~mL} / \mathrm{min}$, respectively.

UV-visible absorption properties test: $\mathrm{AB}$ and $\mathrm{POT}$ were dissolved in DMF, DOX, THF and DCM to form $10 \mu \mathrm{M}$ solutions, respectively. UV-visible absorption spectra were recorded at $25^{\circ} \mathrm{C}$ in quartz cells of $1 \mathrm{~cm}$ path length.

Photoisomerization behaviours test: Polyazo compound with five azobenzene units was dissolved in DMF to form 10 $\mu \mathrm{M}$ solutions. The samples were irradiated with a UV-lamp (ZF-20D Black-box ultraviolet analyzer) which had an intensity maximum of $24 \mathrm{w}$ at a wavelength of $365 \mathrm{~nm}$. The distance between the lamp and the sample cell was $12 \mathrm{~cm}$. For the back-switching, the above photostationary solutions were moved to the natural light and kept in it for some time.

\section{RESULTS AND DISCUSSION}

Synthesis of polyazo compound with five azobenzene units: 1,2-Bis(4-((4,6-bis((4-phenyl diazenyl)phenoxy)-1,3,5triazin-2-yl)oxy)phenyl)diazene (POT) was synthesized by dehydrochlorination reaction between $p$-hydroxyazobenzene ( $p$-HAB), 4,4'-dihydroxyazobenzene (DHAB) and cyanuric chloride (CNC) (Scheme-I). Taking advantage of the temperature-controllable chemo-selectivity of cyanuric chloride,
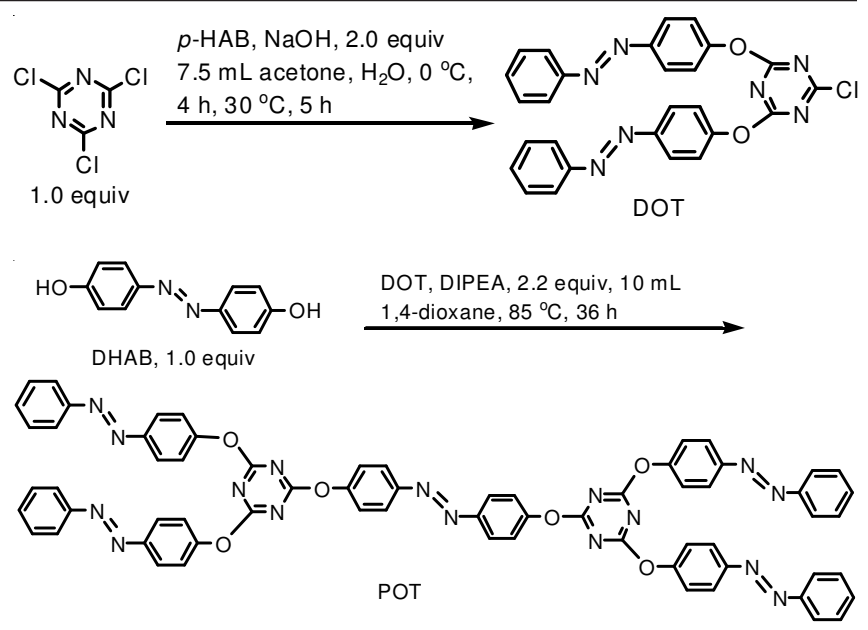

Scheme-I: Synthesis of polyazo compound with five azobenzene units

azophenoxy groups successfully replaced three chlorine atoms and were installed to $[1,3,5]$-triazine rings stepwise through changing the reaction temperature from $0-80^{\circ} \mathrm{C}$. The reaction was carried out under mild conditions. Polyazo compound with five azobenzene units could be obtained via solvent abstersion with moderate yield. It is worth mentioning that a certain amount of compound with three azophenoxy groups linked to the $[1,3,5]$-triazine ring was always produced in the synthesis of POT. The reason may be interpreted that partial 4,4'dihydroxyazobenzene lost one of its two hydroxyl groups during the reaction.

Crystallinity of POT: The crystallinity of POT was studied by means of X-ray powder diffraction (XRD) (Fig. 1). When azobenzene was linked to s-triazine ring by ether bond, both the position and the intensity of the diffraction peaks within 2 theta $(2 \theta)$ range of $2-60^{\circ}$ obviously changed. Compared to azobenzene (AB), apparently, POT had lower degree of orderness which might be caused by the flexibility of the ether bond.

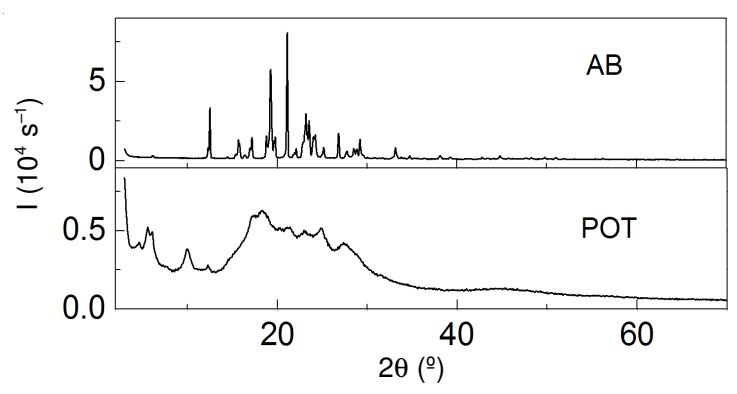

Fig. 1. XRD patterns of POT and azobenzene

Thermostability of polyazo compound with five azobenzene units: The thermostability of POT was investigated using thermogravimetric analysis (TGA) system (Fig. 2). It was interesting that POT showed much better thermostability than $\mathrm{AB}$ although its crystallinity was lower than that of $\mathrm{AB}$. Polyazo compound with five azobenzene units started to greatly lose weight at $388.7^{\circ} \mathrm{C}$, which was primary related to the cleavage of the azo linkages and the ether bonds. When heated to $600{ }^{\circ} \mathrm{C}$, polyazo compound with five azobenzene units still remained its weight with $42.4 \%$, while $\mathrm{AB}$ had decomposed thoroughly around $160^{\circ} \mathrm{C}$. 


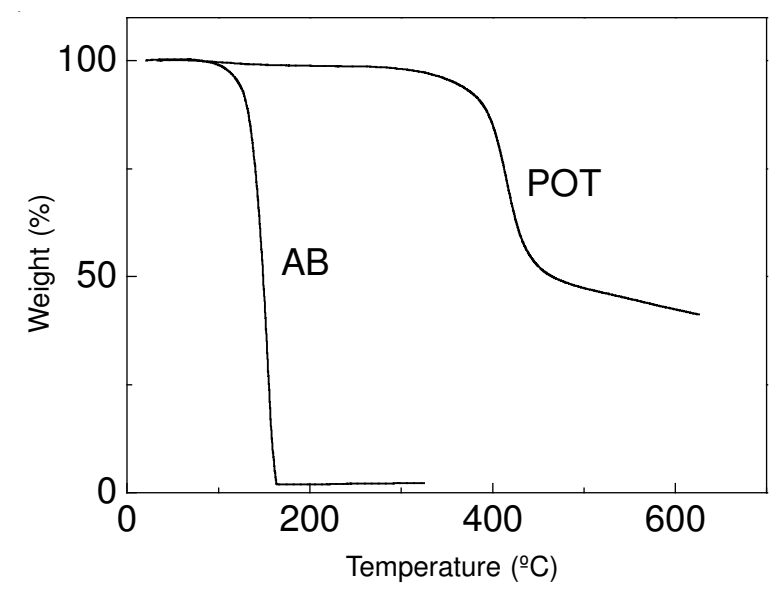

Fig. 2. TGA curves of POT and azobenzene

UV-VIS absorption properties of polyazo compound with five azobenzene units: Polyazo compound with five azobenzene units exhibited typical bimodal UV-VIS absorption profiles of azobenzene in DMF, DOX, THF and DCM. One was the strong symmetry-allowed $\pi \rightarrow \pi^{*}$ transition absorption near $320 \mathrm{~nm}(c a .320 \mathrm{~nm})$ and the other was the weak symmetry-forbidden $\mathrm{n} \rightarrow \pi^{*}$ transition absorption around $440 \mathrm{~nm}(\mathrm{ca} .440 \mathrm{~nm})$. Linking azobenzene to $s$-triazine ring by ether bond led to a small bathochromic shift (less than 13 $\mathrm{nm}$ ) of the band $c a .320 \mathrm{~nm}$ and a smaller hypochromatic shift (less than $7 \mathrm{~nm}$ ) of the band $c a .440 \mathrm{~nm}$, together with an intensity enhancement (Table-2). The wavelength maxima of POT were close to that of $\mathrm{AB}$, while the molar extinction coefficient was approximately five times of that of AB. Furthermore, the fact that the UV-VIS absorption characteristics of POT in DMF, DOX, THF and DCM were similar indicated that the molecule polarity of POT was not greatly affected by solvent and no obvious energy level change in the molecules occurred in different polar solvents.

\begin{tabular}{|c|c|c|c|c|}
\hline \multicolumn{5}{|c|}{$\begin{array}{c}\text { TABLE-1 } \\
\text { UV-VIS ABSORPTION CHARACTERISTICS }\end{array}$} \\
\hline $\begin{array}{c}\text { Compound } \\
\text { solvent }\end{array}$ & $\begin{array}{l}\lambda_{\max 1} \\
(\mathrm{~nm})\end{array}$ & $\begin{array}{c}\varepsilon \\
\left(10^{4} \mathrm{M}^{-1} \mathrm{~cm}^{-1}\right) \\
\end{array}$ & $\begin{array}{l}\lambda_{\max 2} \\
(\mathrm{~nm})\end{array}$ & $\begin{array}{c}\varepsilon \\
\left(10^{4} \mathrm{M}^{-1} \mathrm{~cm}^{-1}\right)\end{array}$ \\
\hline \multicolumn{5}{|c|}{$\mathrm{AB}$} \\
\hline DMF & 318 & 2.02 & 445 & 0.04 \\
\hline DOX & 318 & 1.89 & 445 & 0.04 \\
\hline THF & 321 & 2.16 & 443 & 0.08 \\
\hline DCM & 318 & 1.98 & 440 & 0.07 \\
\hline \multicolumn{5}{|c|}{ POT } \\
\hline DMF & 331 & 8.47 & 438 & 0.40 \\
\hline DOX & 326 & 8.15 & 440 & 0.31 \\
\hline THF & 326 & 8.91 & 438 & 0.39 \\
\hline DCM & 324 & 7.83 & 436 & 0.34 \\
\hline
\end{tabular}

Photoisomerization behaviours of POT: To examine the photoisomerization behaviours of POT, firstly, we irradiated its DMF solutions at $365 \mathrm{~nm}$ and observed a decrease in the $\pi-\pi *$ transition near $320 \mathrm{~nm}$ and a concomitant increase in the $\mathrm{n}-\pi^{*}$ transition around $440 \mathrm{~nm}$ (Fig. 3a). When the solution attained photostationary state, we took it away from the UV light, kept it in the natural light and saw the almost complete recovery of the UV-VIS absorption spectra (Fig. 3b). Therefore, typical reversible E-Z photoisomerization underwent in

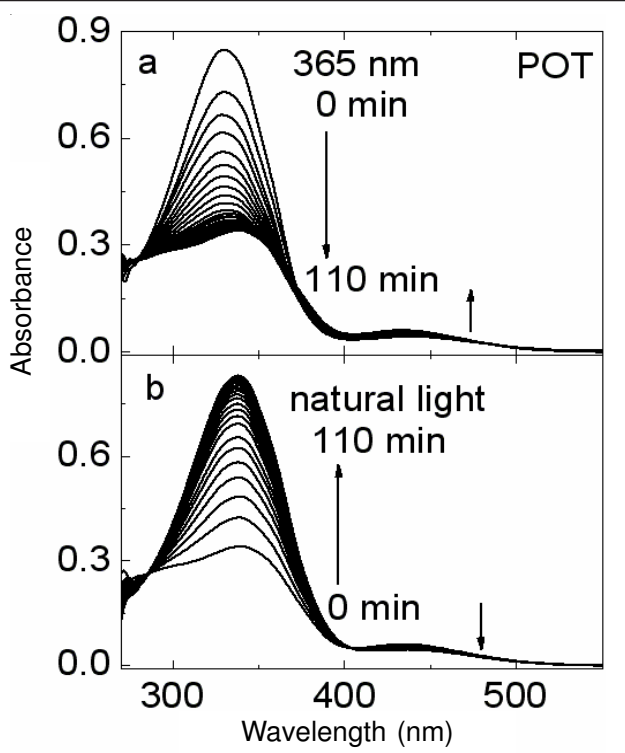

Fig. 3. Changes in UV-VIS absorption spectra of POT (a) irradiation with $365 \mathrm{~nm}$ light, (b) irradiation with natural light $(10 \mu \mathrm{M}, \mathrm{DMF}, 25$ ${ }^{\circ} \mathrm{C}$, interval $5 \mathrm{~min}$ )

POT upon irradiation with UV $(365 \mathrm{~nm})$ or natural light ${ }^{32,33}$. The appearance of the isosbestic points during the course of prolonged irradiation indicated that the isomerization was the only photochemical change and no side reactions such as photodegradations were involved ${ }^{34,35}$. The fact that the UVvisible absorption spectra and their variation upon irradiation were very similar with that of the single azobenzene indicated that no effective electronic communication happened between the multiple azobenzene groups in the same structure and each azobenzene moiety kept its individual absorption and photoisomerization features, which might be caused by the flexibility of the ether linkage.

\section{Conclusion}

An effective method is developed for constructing polyazobenzene with well-defined structure. The synthesized polyazobenzene preserves partial typical characteristics of the single azobenzene (for example, UV-visible absorption and reversible photoisomerization) and at the same time possesses some new features (such as lower crystallinity and better thermostability). It is expected to be used in photonic material areas.

\section{ACKNOWLEDGEMENTS}

The authors thank the financial supports from the National Natural Science Foundation of China (21074085), the open research foundation of the National Engineering Laboratory for Modern Silk, Soochow University (SS115801) and the Priority Academic Program Development of Jiangsu Higher Education Institutions.

\section{REFERENCES}

1. N. Tamai and H. Miyasaka, Chem. Rev., 100, 1875 (2000).

2. M. Pederzoli and J. Pittner, J. Phys. Chem. A, 115, 11136 (2011).

3. T. Cusati, G. Granucci and M. Persico, J. Am. Chem. Soc., 133, 5109 (2011).

4. G.S. Kumar and D.C. Neckers, Chem. Rev., 89, 1915 (1989).

5. H. Rau, Photocromism: Mol. Syst., l, 165 (1990).

6. I. Conti, M. Garavelli and G. Orlandi, J. Am. Chem. Soc., 130, 5216 (2008). 
7. J. Yao, Y. You, H. Liu, L. Dong and C. Xiong, J. Mater. Chem., 46, 3343 (2010)

8. T. Ikeda and O. Tsutsumi, Science, 268, 1873 (1995)

9. M. Suda, M. Nakagawa, T. Iyoda and Y. Einaga, J. Am. Chem. Soc., 129 5538 (2007).

10. W. Chen, Y. Lee and C. Chen, Org. Lett., 12, 1472 (2010).

11. K.M. Lee and T.J. White, Polymer, 3, 1447 (2011).

12. F.Z. Liu, K. Hashimoto and A. Fujishima, Nature, 347, 658 (1990).

13. P.H. Rasmussen, P.S. Ramanujam, S. Hvilsted and R.H. Berg, J. Am. Chem. Soc., 121, 4738 (1999).

14. H. Audorff, K. Kreger, R. Walker, D. Haarer, L. Kador and H.W. Schmidt, Adv. Polym. Sci., 228, 59 (2010).

15. F.K. Bruder, R. Hagen, T. Rölle, M.S. Weiser and T. Fäcke, Angew. Chem. Int. Ed., 50, 4552 (2011).

16. S. Spörlein, H. Carstens, H. Satzger, C. Renner, R. Behrendt, L. Moroder, P. Tavan, W. Zinth and J. Wachtveitl, Proc. Natl. Acad. Sci. USA, 99, 7998 (2002).

17. C. Dugave and L. Demange, Chem. Rev., 103, 2475 (2003).

18. A. Credi, Aust. J. Chem., 59, 157 (2006).

19. T. Hugel, N.B. Holland, A. Cattani, L. Moroder, M. Seitz and H.E. Gaub, Science, 296, 1103 (2002).

20. Y. Yu and T.J. Ikeda, Photochem. Photobiol. C, 5, 247 (2004).

21. M. Chen, H.H. Uang, Y. Zhu, Z. Liu, X. Xing, F. Cheng and Y. Yu, Appl. Phys. A: Mater., 102, 667 (2011)
22. X. Lv, H. Chang and H. Zhang, Opt. Commun., 284, 4991 (2011).

23. H.A. Dabbagh, A. Teimouri and A.N. Chermahini, Dyes Pigments, 73, 239 (2007).

24. M.P. Placidi, A.L. Villaraza, L.S. Natrajan, D. Sykes, A.M. Kenwright and S. Faulkner, J. Am. Chem. Soc., 131, 9916 (2009).

25. J. Liu, F. Qiu, G. Cao, Q. Shen, Z. Cao and D. Yang, J. Appl. Polym. Sci., 121, 2567 (2011).

26. X. Wang, J. Yin and X. Wang, Polymer, 52, 3344 (2011).

27. H. Xie, S. Wang, G. Zhong, Y. Liu, H. Zhang and E. Chen, Macromolecules, 44, 7600 (2011).

28. H. Sogawa, M. Shiotsuki, H. Matsuoka and F. Sanda, Macromolecules, 44, 3338 (2011).

29. W. Zhang, K. Yoshida, M. Fujiki and X. Zhu, Macromolecules, 44, 5105 (2011).

30. D. Ma, Y. Hou and Z. Sun, J. Nat. Sci. Heilongjiang Univ., 24, 446 (2007) In Chinese.

31. X. Liu, X. Lin, D. Xu and K. Zhang, Sci. Technol. Chem. Ind., 14, 23 (2006) In Chinese.

32. W. Chen, Y. Lee and C. Chen, Org. Lett., 12, 1472 (2010).

33. M. Liu, X. Yan, M. Hu, X. Chen, M. Zhang, B. Zheng, X. Hu, S. Shao and F. Huang, Org. Lett., 12, 2558 (2010).

34. Y. Morishima, M. Tsuji and M. Kamachi, Macromolecules, 25, 4406 (1992)

35. C. Saravanan and P. Kannan, Polym. Degrad. Stab., 94, 1001 (2009). 